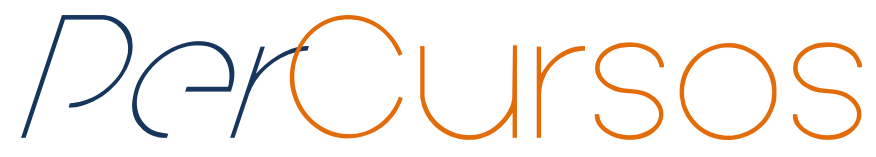

\title{
Uso da palha de buriti: manejo, preservação e tradição do povo Macuxi da comunidade indígena Campo Alegre - Roraima
}

\begin{abstract}
Resumo
Esta pesquisa foi realizada na comunidade indígena Campo Alegre - Terra Indígena São Marcos, localizada no município de Boa Vista - Roraima. Sua principal finalidade é a explicitação do uso da palha do buriti (Mauritia Flexuosa) na cobertura das casas do povo Macuxi, sendo este o recurso mais utilizado pela população. Para a realização deste trabalho, utilizou-se o método indutivo intercultural, através do qual foi possível a construção de um calendário socionatural da comunidade, baseado nos saberes tradicionais e na relação da sociedade com a natureza. Paralelamente, foram utilizadas outras técnicas de pesquisa, como a observação direta e entrevistas, com a finalidade de construir a história da comunidade e da terra indígena, bem como identificar o uso dos recursos naturais. As entrevistas contribuíram para a compreensão do processo social e de relação da sociedade com a natureza, que ocorre na atividade de retirada da palha e cobertura das casas. Verificou-se que a prática de retirada das folhas/palhas do buriti ainda está muito presente no cotidiano dos moradores. Desde o processo de criação da comunidade Campo Alegre até os dias atuais, observa-se que algumas relações sociais, econômicas e aspectos culturais sofrem alterações pela própria organização comunitária, porém sem modificar a prática de uso do buriti para diversas finalidades. Tal hábito tem se perpetuado devido às condições climáticas da área onde está inserida a comunidade, com temperaturas elevadas e, neste contexto, a cobertura com a palha oferece aos moradores um conforto térmico, tornando a vida mais confortável.
\end{abstract}

Palavras-chave: Comunidade Indígena. Índios Macuxi. Roraima. Buriti.

\author{
Mirian Gabriela Gregório Braga \\ Graduada em Gestão Territorial \\ Indígena pela Universidade \\ Federal de Roraima - UFRR. \\ Brasil \\ gabrielamacuxi@gmail.com
}

\section{Maria Bárbara de Magalhães Bethonico}

Doutora em Geografia pela Univ. Federal Fluminense - UFF. Professora da Universidade Federal de Roraima - UFRR. Brasil maria.bethonico@ufrr.br

\section{Para citar este artigo: \\ BRAGA, Mirian Gabriela Gregório; BETHONICO, Maria Bárbara de Magalhães. Uso da palha de buriti: manejo, preservação e tradição do povo Macuxi da comunidade indígena Campo Alegre - Roraima. Revista PerCursos, Florianópolis, v. 19, n.39, p. 177 - 205, jan./abr. 2018.}

DOI: 10.5965/1984724619392018177

http://dx.doi.org/10.5965/1984724619392018177 
The use of buriti straw: management, preservation and tradition of the people Macuxi of the indigenous community Campo Alegre Roraima

\begin{abstract}
This research was conducted in the indigenous community of Campo Alegre - São Marcos indigenous land, located in Boa Vista town. Its main purpose is to explain the use of its buriti straw (Mauritia Flexuosa) in the coverage of houses of Macuxi peoples, which is being used as a resource by its population. For the purpose of this work, the intercultural inductive method was used, which allowed to perform a calendar schedule of its community, based on its traditional knowledge and on the relation of its society to nature. In parallel, other survey techniques were used, such as direct observation and interviews, to construct the history of its community and indigenous land, as well as to identify the use of its natural resources. The interviews contributed to the understanding of the social process and the relation between society and nature, which occurs in the work of straw removal and in the coverage of houses. At the conclusion of this research it was verified that the practice of removal of leaves/buriti straw is still very present in the daily life of its inhabitants, therefore, since the process of its creation of Campo Alegre community to the current day, it has been observed that some social relations, economic and cultural relations were altered by the community organization itself, however without modifying the practice of using buriti for various purposes, including for the coverage of houses. This habit has been perpetuated due to climatic conditions of the area where the community is settled, with high temperatures. In this context, the straw cover offers residents thermal comfort, making life more comfortable.
\end{abstract}

Keywords: Indigenous Community. Macuxi. Roraima. Buriti. 


\section{Introdução}

Os saberes tradicionais estão sempre presentes no cotidiano da população da Comunidade Indígena Campo Alegre, nas atividades das famílias e comunitárias. Estas atividades estão relacionadas diretamente aos conhecimentos dos usos dos recursos naturais que foram ensinados, repassados através das gerações e, também, sofreram modificações com o passar dos anos decorrentes de contatos com outros povos e com os não índios. Vários fatores, como a diversidade cultural e o acesso à tecnologia e materiais industrializados, contribuem para as modificações e até para a diminuição da prática das atividades, incluindo a redução do principal recurso natural da região que é o buriti (Mauritia flexuosa). O buriti é uma espécie de palmeira muito encontrada em ambientes inundados sazonalmente e tem ocorrência nos biomas Amazônia e Cerrado. É muito utilizada por populações humanas, principalmente as folhas, para cobertura de casas, e os frutos, na alimentação.

Segundo Barbosa, Lima e Mourão Junior (2010), o buriti é a espécie de palmeira mais abundante no complexo de savanas que integra o Bioma Amazônia, sendo utilizada por indígenas e populações rurais, além de integrar a alimentação de pessoas que habitam os centros urbanos e que consomem, principalmente, o suco extraído do fruto. Espécie de grande porte, seu caule pode alcançar até 35 metros de altura; possui folhas grandes que formam uma copa arredondada. Apresenta flores de coloração amarelada que surgem de dezembro a abril e os seus frutos em forma de elipsoide castanhoavermelhado possuem uma superfície revestida por escamas brilhantes. A polpa amarela cobre uma semente oval dura e com uma amêndoa comestível; seu período de frutificação vai de dezembro a junho.

Essa espécie exige abundante suprimento de água no solo. Por esta razão, terrenos de várzea e brejos, de solo fofo e úmido, onde se destacam, são indícios seguros de que por ali existe um curso d'água. A espécie possui íntima relação com a água, que atua na dispersão de seus frutos e auxilia na quebra da dormência das sementes.

O buriti marca a paisagem da savana roraimense, conhecida localmente como lavrado, quando se estende ao longo dos igarapés indicando a presença de água, além de 
ser um marco nas divisas territoriais das comunidades indígenas da região do Baixo São Marcos, localizada no município de Boa Vista. A diversidade de usos do buriti pelos moradores das comunidades, como as palhas para artesanato e cobertura de casas, os troncos nas construções, e os frutos para alimentação, vem levando as comunidades a se preocuparem com sua escassez. Essa situação está relacionada ao crescimento populacional em áreas indígenas, o que aumenta a demanda por esse recurso natural (BETHONICO, 2012). Outra preocupação com relação aos buritizais é a sua degradação pela presença do gado e pelas queimadas constantes, que interferem diretamente na sobrevivência da espécie (RESENDE et al, 2012).

Estudos sobre os usos do buriti vêm contribuir para construção e o estabelecimento de estratégias de gestão de território na região e nos levam a refletir sobre como é feito o seu uso nas e entre as comunidades, como estas se organizam para terem esse recurso sempre disponível, apesar dos problemas ambientais e que são comuns na região, como a retirada de palhas sem respeitar os conhecimentos tradicionais, as queimadas descontroladas, o pisoteio de animais como gado e cavalos.

Conhecer o uso do buriti na cobertura das casas tradicionais Macuxi da comunidade indígena Campo Alegre é o objetivo deste estudo. Os objetivos específicos foram voltados ao levantamento de informações sobre os diversos usos do buriti e em refletir sobre como a comunidade se organiza para as retiradas e usos do território no que se refere aos buritizais.

Este levantamento foi realizado através da construção de um calendário socionatural, baseado na proposta metodológica de Gasché e Vela (2012), no qual se trabalha as especificidades das ações humanas com a natureza, associadas à realização de entrevistas com moradores, levantamentos históricos sobre a área de estudo e acompanhamento de algumas atividades relacionadas com a retirada de folhas de buritis, tratamento e cobertura de casas com a palha. O acesso à comunidade indígena foi facilitado por ser a pesquisadora moradora do local e da etnia Macuxi que, ao longo de 
dois anos, voltou-se para a observação e participação nas atividades relacionadas ao buriti'.

Os resultados da pesquisa consistem em um inventário de saberes tradicionais com o uso do buriti, que refletem nas atividades e na relação do homem com o espaço, isto é, em como ocorre o uso de um dos principais recursos existentes na região. Através do estudo da relação entre natureza e sociedade, expressa no calendário, evidenciam-se a cultura e os conhecimentos, permitindo sistematizar os diversos usos dos buritizais, em especial das palhas usadas na cobertura das casas.

\section{A área de estudo: a comunidade indígena campo alegre - TISM}

A Terra Indígena São Marcos/TISM (Figura 1) foi homologada pelo Decreto $n^{\circ} 312$, de 29 de outubro de 1991, com uma área de 654.110 hectares para a reprodução dos povos das etnias Macuxi, Taurepang e Wapichana. Essa área corresponde a mesma porção da Fazenda São Marcos, criada pela Coroa Portuguesa no final do século XVIII, com as fazendas reais de São José e São Bento (BARBOSA, 1993). No final do século XVII e início do século XIX, as fazendas São Joaquim e São Marcos estavam nas mãos de particulares. Após a morte dos proprietários e sem deixar herdeiros, as áreas das fazendas são incorporadas ao patrimônio da Coroa Portuguesa (VIEIRA; GOMES FILHO, 2013). Segundo Barbosa (1993), somente a fazenda São Marcos resistiu ao tempo e à ocupação por fazendeiros. Nas proximidades da sede da fazenda São Marcos encontravam-se malocas indígenas, uma situação que as levou a ficar sob responsabilidade do Serviço de Proteção do Índio/SPI desde 1916 e, posteriormente, a Fundação Nacional do Índio/FUNAI passou a administrá-la. Desde a criação da FUNAI, a Fazenda São Marcos não era destinada aos indígenas, mas sim uma fazenda do Estado, onde viviam índios, e o SPI usou o espaço mais como uma base operativa do que como um local que desenvolvesse trabalhos em favor dos indígenas. A criação dessas fazendas

\footnotetext{
1 A pesquisa integra os resultados do Projeto Observatório de Educação Escolar Indígena, financiamento da CAPES/2012-2016.
} 
foi uma estratégia de delimitação e ocupação da região do vale do Rio Branco pelo império português que, até então, era vista como garantia de posse de terra.

Figura 1 - Localização geográfica da Terra Indígena São Marcos

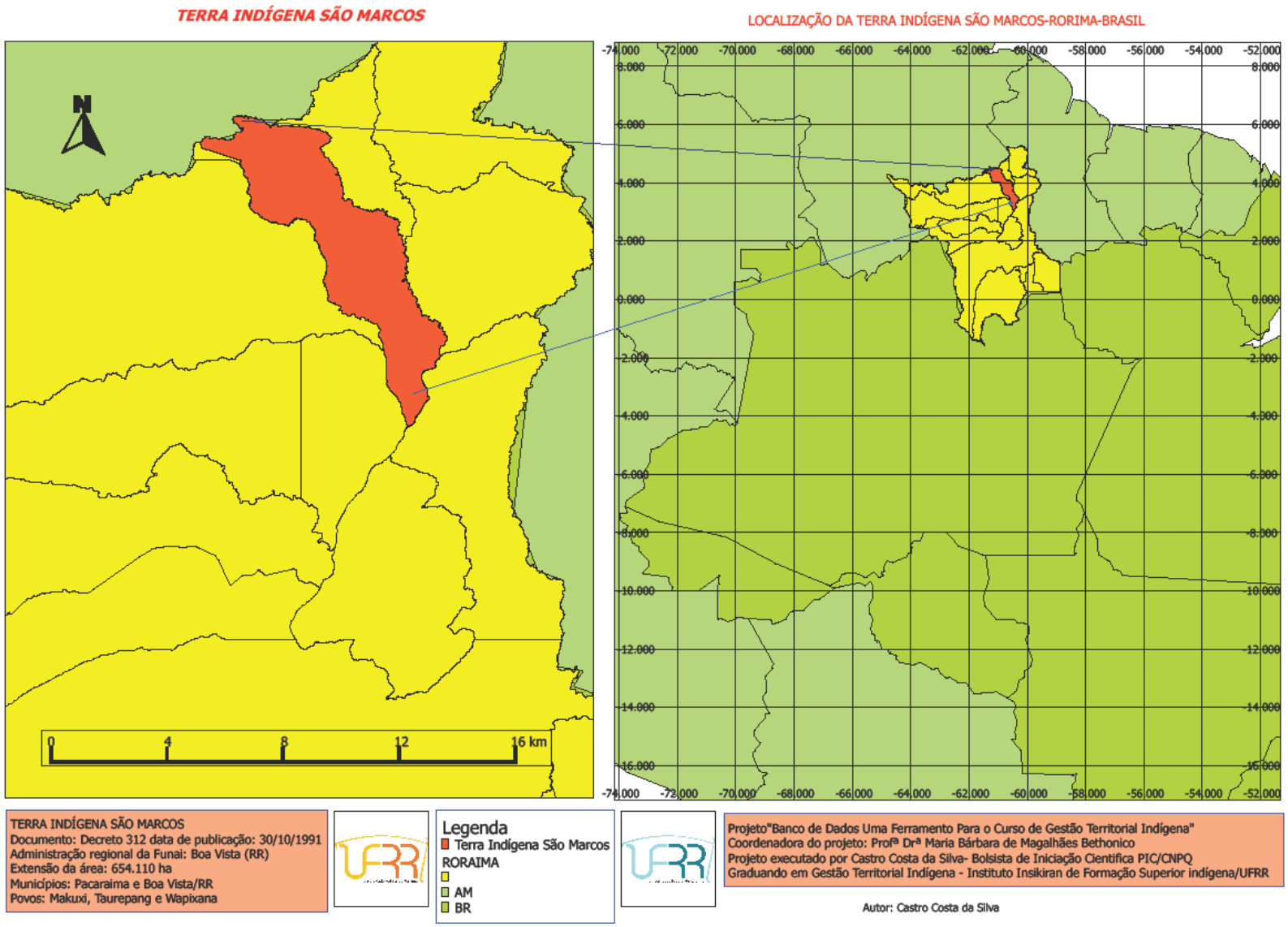


A terra indígena São Marcos tem duas divisas em dois municípios, Pacaraima e Boa Vista e possui 44 comunidades organizadas em três etnorregiões (Alto, Médio e Baixo São Marcos), criadas para facilitar a administração e gestão do território. A demarcação desta terra indígena ocorreu em 1991. Nos últimos 15 anos, o crescimento populacional nesta região dobrou, conforme demonstrado na Tabela 1. O crescimento populacional se repete nas 32 terras indígenas do estado de Roraima, bem como no restante do Brasil, tornando-se um dos desafios para a gestão do território (BETHONICO, 2012). A Secretaria Especial de Saúde Indígena/SESAI é o principal órgão que fornece dados sobre a população nas comunidades indígenas em Roraima, através do Distrito Sanitário Leste/DSEI. Segundo dados deste órgão, no ano de 2016 a população total da Terra Indígena São Marcos era de 6.096 moradores, sendo 224 pessoas pertencentes à Comunidade Campo Alegre, divididas em 59 famílias das etnias Macuxi e Wapichana ${ }^{2}$. Os povos que compõem essa comunidade pertencem a dois grupos linguísticos: os Macuxi, ao grupo Karib, e os Wapichana, ao grupo Aruak.

A Terra Indígena São Marcos (TISM) tem uma composição paisagística variada. Nas regiões do Baixo e Médio São Marcos, temos o predomínio do lavrado (savanas ou campos cerrados), uma extensa superfície aplainada com mosaico de suaves colinas entremeadas de depressões com buritizais e manchas esparsas de florestas, como ilhas. Na parte norte da terra indígena, encontramos um relevo mais movimentado, a Serra de Pacaraima, recoberta de floresta ombrófila densa e com presença de nascentes de expressivos rios, como o Surumu.

\footnotetext{
2 Segundo o levantamento realizado pela FUNASA/Conselho Indígena de Roraima-CIR, no ano de 2000, a comunidade de Campo Alegre possuía uma população de 112 moradores.
} 
Tabela 1 - População da Terra Indígena São Marcos - 2010 - 2015

\begin{tabular}{|l|c|l|l|l|l|}
\hline \multirow{2}{*}{ Etnorregião } & \multirow{2}{*}{$\begin{array}{l}\text { Total de } \\
\text { comunidades* }\end{array}$} & \multicolumn{4}{|c|}{ População total } \\
\cline { 3 - 6 } & & 2000 & 2005 & 2010 & 2015 \\
\hline Baixo São Marcos & 8 & 1.080 & 1.608 & 1.782 & 1397 \\
\hline Médio São Marcos & 13 & 473 & 624 & 747 & 1.489 \\
\hline Alto São Marcos & 23 & 1.046 & 1.874 & 2.073 & 2896 \\
\hline Total & 44 & 2.599 & 4.106 & 4.602 & 5.782 \\
\hline
\end{tabular}

* Total de comunidades de acordo com o Censo SESAI de 2015. Algumas comunidades foram criadas ao longo do período constante nesta tabela, considerando que existe uma dinâmica no interior das terras indígenas de criação de comunidades por famílias que buscam novas áreas para roças e demais atividades de subsistência.

A comunidade indígena Campo Alegre está localizada na etnorregião ${ }^{3}$ do Baixo São Marcos, município de Boa Vista, a 56 km da capital Boa Vista (Figura 2), em uma área de lavrado e com igarapés que possuem buritis ao longo de seu curso. Segundo os moradores mais antigos da comunidade, o buriti foi o principal recurso que influenciou na escolha do local para se fixarem. A grande quantidade de buritizais na região era sinônimo de fartura, tanto relacionados à caça e pesca, quanto aos frutos e à disponibilidade de recursos naturais (palha) para construção de suas moradias.

3 Uma etnorregião refere-se à denominação de um espaço geográfico que é dividido segundo critérios dos povos que o ocupam. 


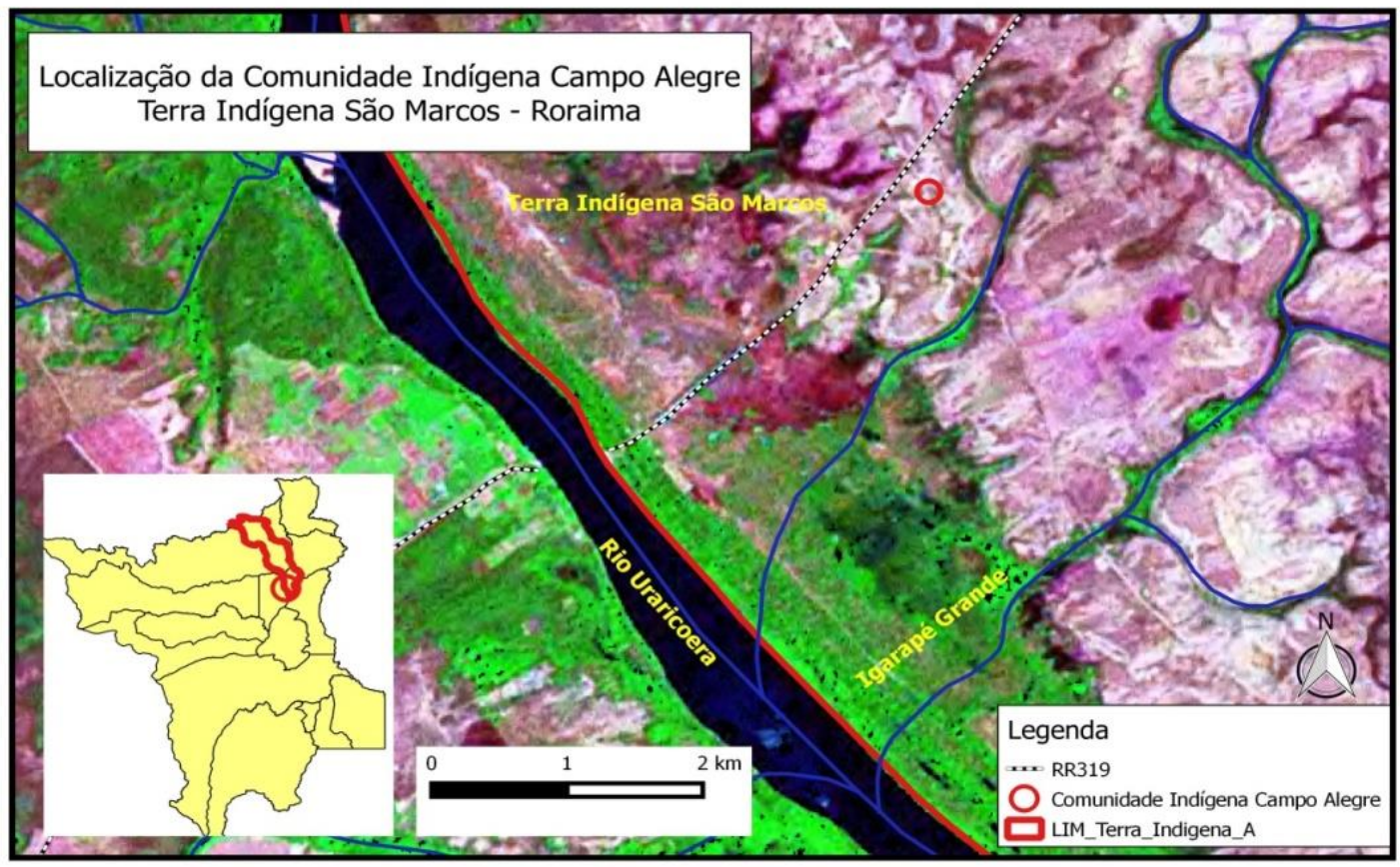

Segundo entrevistas realizadas com lideranças locais, a comunidade de Campo Alegre iniciou-se a partir de um acordo entre o Sr. Lino Augusto da Silva e o Sr. Raimundo Nascimento, mais conhecido como Sr. Mundico, que era na época tuxaua ${ }^{4}$ da comunidade Vista Alegre. O Sr. Lino era morador da comunidade indígena do Xumina, localizada na Terra Indígena Raposa Serra do Sol, e foi morar no novo local com a família em 1978, motivado pelo fato de que em sua antiga comunidade já não conseguia espaço para sua criação e roça. Com o tempo, novas famílias foram morar na nova comunidade.

Atualmente, a comunidade se organiza através de reuniões mensais que acontecem na primeira semana de cada mês, quando a população tem acesso às informações repassadas pelo tuxaua e por outras lideranças como o vaqueiro, capataz dos homens e das mulheres, os líderes das igrejas católica e evangélicas, os diretores das escolas, agentes de saúde indígena (AIS) e de saneamento (AISAN). É o momento, também, de se organizarem para as atividades comunitárias, como a retirada de palhas para cobertura de barracões e casas, retirada de madeiras para construção de cercados e

4 O tuxaua é a denominação da liderança máxima de uma comunidade indígena, eleito pela comunidade em uma assembleia. 
currais, a vacinação de gado, dentre outras coisas. Além das reuniões mensais, os moradores sempre procuram organizar eventos voltados para a cultura indígena local, como as danças de Parixara, Tukui e Areruia, competições de arco e flecha, corrida de toras de madeiras, exposição e venda de artesanatos e de produtos regionais como farinha, beijú, damurida (alimento a base de peixe ou caça e temperado com sal e pimenta), caxiri (bebida a base de mandioca), entre outros.

\section{Procedimentos metodológicos}

Para alcançar os objetivos da pesquisa, realizou-se, inicialmente, um levantamento bibliográfico com a finalidade de dar suporte para as discussões e análises posteriores. De forma complementar, foram realizados trabalhos de campo, nos anos de 2015 e 2016, para levantamento de informações; nesses momentos, foram realizadas entrevistas para a construção do calendário e levantamento dos diversos usos do buriti na comunidade, envolvendo os moradores mais antigos e os que ainda utilizam esta espécie para outros fins - como o artesanal, para alimentação e confecção de adubo -, no total de seis moradores. O trabalho foi feito através de levantamentos da atual situação ambiental dentro da comunidade e de todas as atividades voltadas ao uso do buriti anualmente, sendo elas explicitadas de acordo com o método do calendário socionatural (GASCHÉ; VELA, 2012). As atividades sociais são entendidas como unidades de análise para poder explicitar e compreender como funcionam e se organizam os conhecimentos indígenas (REPETTO; CARVALHO, 2016, p. 3).

As visitas de campo foram realizadas em algumas áreas de buritizais e tiveram o objetivo de demonstrar como se encontra a situação ambiental do buritizal.

Durante as entrevistas, foram realizados os levantamentos de dados e de informações que permitiram a construção do calendário socionatural, que possui uma organização própria. Essas informações foram complementadas pelo conhecimento próprio da pesquisadora, uma vez que é moradora da comunidade. 


\section{Proposta metodológica do calendário socionatural}

A cultura indígena está diretamente relacionada ao meio ambiente, ao cultivo e à subsistência, tendo a terra como a mãe que fornece os frutos, alimenta o povo, proporciona a vida e o bem-estar da comunidade. Dessa forma, a comunidade indígena tem uma atenção especial para com o meio ambiente, os ciclos climáticos e as estações definidas, pois são elas que delimitarão o melhor período para as plantações, cultivos, o tempo certo para se usar certas plantas e de consumir certos alimentos mantendo, assim, um equilíbrio em seu habitat. Neste sentido, “o movimento histórico do desenvolvimento humano nos permite compreender que o homem é essencialmente um ser de natureza social, isto é, a sua fonte de hominização provém da sua vida em sociedade, no seio da cultura gerada por toda humanidade" (CEDRO; MOURA, 2012, p. 43).

Para buscar o entendimento dessa relação que se estabelece com o meio, optamos pela metodologia dos calendários socionaturais, partindo da proposta que foi introduzida, inicialmente, na formação de professores indígenas em Roraima, por professores e estudantes do curso de Licenciatura Intercultural e, posteriormente, do curso de Gestão Territorial Indígena do Instituto Insikiran de Formação Superior Indígena / UFRR ${ }^{5}$.

A construção desses calendários segue o Método Indutivo Intercultural/MII, que se fundamenta em diversas experiências em países como Peru, México, Colômbia e Brasil na construção de propostas pedagógicas inovadoras para escolas indígenas. Tem como marco principal o modo de vida na comunidade, todos os seus saberes tradicionais e conhecimentos indígenas, partindo do pressuposto de que a comunidade é fonte de conhecimento e a cultura indígena está refletida nas atividades cotidianas. Para Repetto e Carvalho (2015, p. 1), “o marco teórico do Método Indutivo Intercultural vem sendo objeto de reflexões na América Latina e se fundamenta em diversas experiências, na tentativa de construir propostas pedagógicas inovadoras para escolas indígenas, que sejam do interesse dos próprios sujeitos do processo escolar." Tem como finalidade relacionar o

\footnotetext{
5 O Instituto Insikiran de Formação Superior Indígena integra a Universidade Federal de Roraima. Foi criado em 2001 como Núcleo e, em 2009, transformado em Instituto. Atende exclusivamente alunos indígenas em três áreas de formação: licenciatura intercultural, gestão do território e saúde.
} 
cotidiano do povo na comunidade, promovendo uma reflexão coletiva sobre as realidades das comunidades indígenas no uso dos recursos naturais, quando as atividades são organizadas em relação ao tempo e ao uso do seu território. A partir dessas atividades é possível estabelecer uma reflexão sobre a importância da relação entre as pessoas e o território, seus conhecimentos tradicionais como formas didáticas para interculturalidade.

Segundo Gasché e Vela (2012), a sociedade busca na natureza a satisfação de suas necessidades, tendo assim uma relação inseparável, sugerindo a utilização do conceito de "socionatureza" para expressar essa relação. A comunidade indígena Campo Alegre se relaciona com a natureza de acordo com as suas necessidades, sendo elas diretas (produção de alimentos, caça, pesca) ou indiretas (preservação dos recursos naturais) trazendo, assim, constantes modificações tanto para o modo de vida quanto para o meio ambiente. Essas modificações estão expressas nas atividades que realizam no seu cotidiano. Assim,

El medio natural, el lenguaje, la sociedad y la cultura que ésta produce están íntimamente amalgamados en la estructura de la actividad. El análisis de la actividad nos permite comprender el arraigo de cada persona en su universo sócio-cultural y linguístico y, a través de ello, en su medio natural, en el cual las personas en sociedad impactan mediante sus accesos a los recursos naturales, los que, a su vez, son parte del universo sócio-cultural y linguístico. La estructura de las actividades contiene el proceso vivencial y social - flujos de materia, energía y información - que la fuerza humana realiza en el medio natural, entendido como totalidad de las disponibilidades de recursos naturales (la biodiversidad) y de su funcionamento eco-sistemático, eventualmente modificado por el ser humano. (GASCHÉ; VELA, 2012, p. 117)

O calendário socionatural nos permite pensar a inter-relação com a natureza ao longo de um ano a partir de variáveis específicas. Permite, assim, montar um calendário anual que apresente as principais atividades humanas e os diferentes conhecimentos sobre a natureza associados a elas.

O Calendário Socionatural possibilita o trabalho de pesquisa a partir dos seguintes indicadores: 
1) Atividades comunitárias: ações feitas pelos homens e mulheres;

2) Atividades das crianças: papel da criança dentro das atividades comunitárias, familiares e escolares;

3) Conhecimentos climáticos: indica qual a relação das atividades realizadas anualmente de acordo com o saber tradicional;

4) Conhecimentos astronômicos: período de determinadas atividades como por exemplo, a retirada da palha;

5) Conhecimentos sobre os animais: períodos de caça, pesca, e etc.;

6) Conhecimentos sobre os vegetais: período em que as plantas estão florindo, com frutos e etc.;

7) Problemas socioambientais e de saúde: indicam quais são as dificuldades enfrentadas dentro da comunidade.

Essas informações permitem compreender as complexas relações entre sociedade e natureza, isto é, o meio em que vivem, os recursos naturais existentes e disponíveis e a forma como são utilizados, considerando essas informações importantes para a gestão do território.

\section{O calendário socionatural da comunidade Campo Alegre - TISM}

As principais atividades realizadas pelos moradores da comunidade indígena Campo Alegre mostram como se relacionam as ações humanas com os diferentes ciclos da natureza ao longo do ano, sendo estudados os seis indicativos: clima, vegetais, animais, socioambientais, astronômicos, atividades comunitárias e atividades das crianças. Através dessas atividades, o povo Macuxi mantém cotidianamente vários saberes tradicionais que registram desde os primeiros contatos no século XVII e a maior presença de não índios, a partir do século XVII. As atividades estão organizadas nos meses, nos quais se poderá ter uma visão mais ampla das atividades coletivas.

Esses dados foram organizados em um quadro baseado na construção do calendário socionatural (Quadro 1 e Quadro 2), permitindo uma melhor visualização das 
informações coletadas junto aos moradores da comunidade, destacando as atividades realizadas durante o ano, organizadas por sete indicadores que facilitam a explicitação das ações e a relação da comunidade com a natureza.

Quadro 1 - Calendário socionatural das atividades da comunidade indígena Campo Alegre $-1^{\circ}$ semestre

\begin{tabular}{|c|c|c|c|c|c|c|}
\hline Indicadores & Janeiro & Fevereiro & Março & Abril & Maio & Junho \\
\hline Astronômicos & $\begin{array}{l}\text { No primeiro dia do } \\
\text { ano se antes do } \\
\text { nascer do sol } \\
\text { aparecer uma } \\
\text { nuvem escura é } \\
\text { porque o inverno vai } \\
\text { ser muito forte } \\
\text { durante o ano. }\end{array}$ & & & $\begin{array}{l}\text { Tamîkan aparece a } \\
\text { oeste no fim de tarde } \\
\text { as } 16 \text {, indicando a } \\
\text { chegada do inverno. } \\
\text { Um indicador } \\
\text { bastante importante } \\
\text { para o povo macuxi. }\end{array}$ & & \\
\hline Climáticos & $\begin{array}{l}\text { Verão, essa é a } \\
\text { época em que os } \\
\text { moradores que } \\
\text { construirão casas ou } \\
\text { vão reformar } \\
\text { trabalham mais. }\end{array}$ & $\begin{array}{l}\text { Verão - os } \\
\text { igarapés estão } \\
\text { todos secos. }\end{array}$ & $\begin{array}{l}\text { Primeira chuva } \\
\text { anunciando } \\
\text { inverno, mas ainda } \\
\text { se pode tirar a } \\
\text { palha. }\end{array}$ & $\begin{array}{l}\text { Início do inverno } \\
\text { fraco. } \\
\text { Ultimo período para } \\
\text { tirar palha para cobrir } \\
\text { casa. }\end{array}$ & & $\begin{array}{l}\text { Inverno. } \\
\text { Não se pode tirar } \\
\text { palha para cobrir } \\
\text { casa. }\end{array}$ \\
\hline Animais & & & $\begin{array}{l}\text { Época que os } \\
\text { papagaios estão } \\
\text { com filhote. } \\
\text { Os peixes estão } \\
\text { "ovados". }\end{array}$ & $\begin{array}{l}\text { Grilo, saúva, manivara } \\
\text { e cupim saem na } \\
\text { primeira chuva } \\
\text { anunciando a } \\
\text { chegada do inverno. } \\
\text { O período da tirada } \\
\text { de palha está } \\
\text { suspensa. }\end{array}$ & & \\
\hline Vegetais & & & $\begin{array}{l}\text { O fruto do Buriti } \\
\text { está maduro. Os } \\
\text { macuxi colhem os } \\
\text { frutos para se } \\
\text { alimentarem. }\end{array}$ & $\begin{array}{l}\text { Os frutos de buriti } \\
\text { que não foram } \\
\text { colhidos são } \\
\text { aproveitados pelos } \\
\text { animais. }\end{array}$ & $\begin{array}{l}\text { Não se tira a } \\
\text { palha de buriti } \\
\text { por causa do } \\
\text { inverno. }\end{array}$ & \\
\hline $\begin{array}{l}\text { Problemas } \\
\text { Sociais, } \\
\text { Ambientais e } \\
\text { de Saúde }\end{array}$ & & $\begin{array}{l}\text { O rio, igarapés e } \\
\text { lagos começam a } \\
\text { secar, o que por } \\
\text { um lado facilita o } \\
\text { acesso para tirar } \\
\text { os frutos e as } \\
\text { palhas, mas } \\
\text { também, não } \\
\text { impede a chegada } \\
\text { das queimadas. }\end{array}$ & $\begin{array}{l}\text { Se inicia o ciclo de } \\
\text { queimadas, onde os } \\
\text { buritizais sempre } \\
\text { são bastante } \\
\text { afetados, } \\
\text { principalmente as } \\
\text { árvores menores. }\end{array}$ & & & $\begin{array}{l}\text { Estradas ficam } \\
\text { interditadas pela } \\
\text { água, } \\
\text { dificultando o } \\
\text { tráfego do } \\
\text { transporte para } \\
\text { o carregamento } \\
\text { da palha. }\end{array}$ \\
\hline $\begin{array}{l}\text { Atividades } \\
\text { Comunitária }\end{array}$ & & $\begin{array}{l}\text { Reunião } \\
\text { comunitária para } \\
\text { organização dos } \\
\text { trabalhos } \\
\text { comunitários, } \\
\text { incluindo a } \\
\text { reforma das casas }\end{array}$ & $\begin{array}{l}\text { Reunião } \\
\text { comunitária para } \\
\text { organização dos } \\
\text { eventos no } \\
\text { decorrer do ano. } \\
\text { Retirada de palha } \\
\text { de buriti. }\end{array}$ & $\begin{array}{l}\text { Festejo da Mostra de } \\
\text { Danças Indígenas } \\
\text { Tradicionais Parixara, } \\
\text { Tukui, Areruya e } \\
\text { Feira Comunitária. } \\
\text { Nesse momento } \\
\text { todos os }\end{array}$ & & $\begin{array}{l}\text { Festejo do } \\
\text { aniversário da } \\
\text { comunidade. }\end{array}$ \\
\hline
\end{tabular}




\begin{tabular}{|l|l|l|l|l|l|}
\hline & & $\begin{array}{l}\text { que precisam } \\
\text { renovar a } \\
\text { cobertura de } \\
\text { palha. }\end{array}$ & $\begin{array}{l}\text { participantes usam a } \\
\text { palha do buriti para a } \\
\text { confecção do traje de } \\
\text { dança e para } \\
\text { produção de } \\
\text { artesanatos. } \\
\text { O fruto, o caranã e a } \\
\text { capemba do buriti } \\
\text { são sempre utilizados } \\
\text { na decoração da } \\
\text { comunidade em } \\
\text { época de festejos. }\end{array}$ & \\
\hline Atividades \\
Crianças
\end{tabular}

Quadro 2 - Calendário socionatural das atividades da comunidade indígena Campo Alegre $-2^{\circ}$ semestre

\begin{tabular}{|c|c|c|c|c|c|c|}
\hline Indicadores & Julho & Agosto & Setembro & Outubro & Novembro & Dezembro \\
\hline \multicolumn{7}{|l|}{ Astronômicos } \\
\hline Climáticos & $\begin{array}{l}\text { Inverno pesado. } \\
\text { Não se pode tirar } \\
\text { palha para cobrir } \\
\text { casa. }\end{array}$ & $\begin{array}{l}\text { Inverno fraco - Início } \\
\text { das trovoadas. }\end{array}$ & $\begin{array}{l}\text { Época das } \\
\text { trovoadas. }\end{array}$ & $\begin{array}{l}\text { Outono - Início de } \\
\text { primavera. } \\
\text { Anuncia a volta da } \\
\text { retirada de palha para } \\
\text { cobrir as casas macuxi }\end{array}$ & $\begin{array}{l}\text { Primavera. } \\
\text { Pode trabalhar } \\
\text { com a palha } \\
\text { para cobrir } \\
\text { casa. }\end{array}$ & $\begin{array}{l}\text { Primavera - } \\
\text { Verão. } \\
\text { Pode trabalhar } \\
\text { com a palha } \\
\text { para cobrir } \\
\text { casas. }\end{array}$ \\
\hline Animais & & $\begin{array}{l}\text { Os animais estão } \\
\text { venenosos. } \\
\text { Esse seria um dos } \\
\text { motivos para não se } \\
\text { tirar a palha no } \\
\text { inverno devido aos } \\
\text { vários acidentes com } \\
\text { esses animais que } \\
\text { ocorrem; de acordo } \\
\text { com o saber } \\
\text { tradicional macuxi } \\
\text { devemos respeitar a } \\
\text { época venenosa dos } \\
\text { animais, pois se for } \\
\text { picado por algum } \\
\text { animal nessa época } \\
\text { é muito difícil de se } \\
\text { curar. }\end{array}$ & & & & \\
\hline
\end{tabular}




\begin{tabular}{|l|l|l|l|l|l|l|}
\hline Vegetais & & & $\begin{array}{l}\text { As famílias voltam } \\
\text { a tirar a palha de } \\
\text { buriti porque o } \\
\text { inverno terminou. }\end{array}$ & & $\begin{array}{l}\text { Nasce o "olho } \\
\text { do buriti" que } \\
\text { vai se tornar } \\
\text { novas palhas. }\end{array}$ & \\
\hline $\begin{array}{l}\text { Problemas } \\
\text { Sociais, } \\
\text { Ambientais e } \\
\text { de Saúde }\end{array}$ & & & & & & $\begin{array}{l}\text { Novo ciclo de } \\
\text { queimadas. }\end{array}$ \\
\hline $\begin{array}{l}\text { Atividades } \\
\text { Comunitária }\end{array}$ & & & & & & \\
\hline $\begin{array}{l}\text { Atividades } \\
\text { Crianças }\end{array}$ & & & $\begin{array}{l}\text { Desfile das escolas } \\
\text { da região do Baixo } \\
\text { São Marcos. Uma } \\
\text { parte das crianças } \\
\text { desfilam usando } \\
\text { traje tradicional } \\
\text { feito com a palha } \\
\text { de buriti. }\end{array}$ & & & \\
\hline
\end{tabular}

A comunidade ou a família que vai efetivar a retirada das folhas inicia o processo com a escolha do buritizal. Essa escolha está relacionada à quantidade de folhas necessárias, à distância que o buritizal se encontra da comunidade e a disponibilidade de buritis com folhas prontas para serem retiradas. Utilizam uma faca presa em uma vara de madeira que é, normalmente, retirada da própria vegetação existente na comunidade. É uma atividade realizada por homens e, para as mulheres, cabe a tarefa de organizar as folhas em um local para que sequem. A melhor época de retirada das folhas do buriti corresponde ao verão em Roraima, entre os meses de outubro e março, época em que não temos chuvas frequentes e os igarapés não estão cheios. O inverno atrapalha, principalmente com relação ao transporte da palha até o local onde ela será utilizada, pois, geralmente, os buritizais estão em locais úmidos que atolam, dificultando o trânsito de veículos. A chuva também apodrece facilmente as palhas já que elas são retiradas verdes e precisam do sol para secar (em 80\%), para serem amarradas e arrumadas para formação do telhado das construções.

As palhas retiradas dos buritis servem, também, para a confecção de vestimentas e artesanatos que ocorrem, principalmente, no mês de março. As vestimentas ou trajes são usados pela comunidade nas festividades, quando fazem a dança do Parixara, manifestação típica entre os povos Macuxi e Wapichana que envolve os moradores da 
comunidade e é realizada em momentos festivos. Na cultura Macuxi existem dois tipos de trajes utilizados para apresentação de danças, ambos feitos do olho de buriti: um utiliza a fibra do olho de buriti e a peça dura mais tempo; o outro é feito com a palha do olho de buriti inteira e verde, e esse traje só pode ser utilizado no dia em que é confeccionado, pois logo perde o formato e seca.

Nesta parte da Amazônia, consideramos apenas duas estações, a chuva ou inverno e a seca ou verão. Nos indicadores climáticos aparecem esses dois momentos que apontamos de retirada dos frutos. O buriti amadurece no início do inverno e sua utilização é indicada pela cor da casca, que deve estar bem escura. Os moradores retiram os cachos e colocam dentro de sacos de fibra que vão ficar de molho no igarapé para amolecer. Algumas pessoas levam para casa e deixam de molho na água dentro de baldes, exigindo a observação deste durante vários dias, até se conseguir o ponto em que poderá ser transformado em bebida, ou o conhecido 'vinho de buriti', espécie de suco produzido a partir da polpa do buriti.

\section{O buriti e seu uso na comunidade indígena Campo Alegre}

Para os Macuxi da comunidade indígena de Campo Alegre, o buriti foi o principal recurso que influenciou na escolha do local para se fixarem, conforme informações dos entrevistados, sendo sempre chamado por eles de "árvore da vida" por ter uma grande utilidade, desde a alimentação até a confecção de adubo. Além da grande quantidade de buritizais na região, a presença da espécie era sinônimo de fartura, tanto relacionada à caça (presença de vários animais nos buritizais por causa da água e do fruto) e pesca, quanto aos frutos e à construção de suas moradias. Os buritizais possuem uma importância especial no que se refere ao equilíbrio dos ecossistemas em que estão inseridos. Eles auxiliam na manutenção dos rios e igarapés, evitando o seu assoreamento; contribuem, também, para a manutenção da umidade do solo nos períodos de estiagem.

O fruto do buriti - kuwai, em Macuxi - possui várias utilidades, dentre elas a produção da bebida já mencionada, conhecida por vinho de buriti, sendo este a forma mais consumida pela população da comunidade, até para a comercialização local. Da 
polpa de seus frutos é extraído um óleo comestível que possui altos teores de vitamina $\mathrm{A}$ e C, e é muito utilizado para a produção de sorvetes, cremes, geleias, licores e vitaminas. Esse mesmo óleo é utilizado contra queimaduras, por possuir um efeito calmante da dor e potente cicatrizante. O uso medicinal está mais associado ao óleo extraído da polpa dos frutos, com propriedades energéticas e vermífugas. Tem sido empregado recentemente pela indústria cosmética, entrando na composição de sabonetes, cremes, shampoos e pomadas.

Cada buriti adulto possui de 20 a 30 folhas que são compostas por três partes: a capemba, o talo e a palha. A capemba é a parte mais larga do talo que fixa a folha ao caule do buriti; ela é bastante utilizada na confecção de artesanatos como cestas para colocar alimentos. O talo que também é chamado de caranã pelos Macuxi e é coberto por uma fibra dura conhecida como tala, que pode ser retirada para tecer cestos e outros artesanatos, além de ser usado na construção das janelas. A palha é o restante da folha, que é usada para cobrir o telhado das casas; também é utilizada para artesanato, extraindo a sua fibra quando ainda está verde. Geralmente as fibras do "olho do buriti" são as mais retiradas e essa ação, muitas vezes feita de modo excessivo, acaba retardando o seu crescimento e a produção de novas folhas.

\section{Cobrir casa com palha de buriti e os saberes tradicionais dos Macuxi da}

\section{comunidade indígena Campo Alegre - TISM}

Os povos indígenas dominam um imenso conhecimento tradicional associado à biodiversidade existente em seus territórios que, além de lhes garantir a capacidade de explorar sustentavelmente esse território no passado, ainda hoje tem importância econômica e ambiental, ressaltando assim os saberes tradicionais que ainda são praticados pela população da comunidade. Considera-se como esse conhecimento é compartilhado por outros povos, pois, segundo os entrevistados, não se pode afirmar que a atividade de cobrir a casa com palha de buriti seja um aprendizado só deles, mas sim de todos que possuem o recurso em sua região.

No estado de Roraima ainda é muito pouca a presença de trabalhos voltados para 
as questões dos impactos ambientais causados pela própria população indígena e o uso sem manejo dos recursos presentes dentro de suas terras. Os trabalhos com a Mauritia Flexuosa dentro das terras indígenas são, em sua maioria, voltados a projetos escolares com o manejo de mudas, mas dificilmente falam do acompanhamento dessas mudas e de como é feito o seu manejo pelas pessoas que são beneficiadas.

Fazer parte de algumas atividades comunitárias contribuiu para as explicitações do saber tradicional de como se relacionar com a natureza, do uso correto dos recursos que ali existem, em especial dos buritizais, e qual o significado dessas práticas para a população. Os saberes tradicionais citados pelos Macuxi são "ensinados assim", quando se referem às formas de uso dos recursos naturais. Desde quando se lembram das histórias de seus antepassados, afirmam que não sabem certamente dizer o porquê das regras que seguem na realização das atividades. Durante as entrevistas, alguns participantes relataram já terem testado fazer a retirada da palha fora do período que Ihes foi ensinado e comprovaram que a palha estraga, causando um prejuízo para a natureza por causa do desperdício, comprovado pela falta de uso dos saberes tradicionais; outro prejuízo é para a família que está morando na casa que foi coberta pela palha que foi tirada "no tempo errado", ou seja, que não foi tirada na lua minguante, pois sua durabilidade é muito menor.

Considera-se que a palha do buriti deve ser retirada somente na lua minguante, chamada de lua escura ou noite escura, quando animais, como a lagartinha preta Yakî, que comem as palhas e também as madeiras não saem para se alimentar de um leite que só é produzido nas outras fases da lua que chamam de Awekînaatî. Esse leite é produzido em todas as plantas e os bichos saem durante a noite para se alimentar, quando se tem uma noite clara. Os Macuxi dizem que nessa época todos os bichos da terra saem, tanto os que podemos ver, quanto os que não podemos ver, que são os seres espirituais. Alguns ainda dizem que, quando a noite está clara, todas as plantas ficam fracas, vulneráveis aos ataques de seus predadores, como as lagartas, besouros e outros animais, por isso que não tiram palha e nem madeira nessa época. As casas cobertas com palha de buriti são denominadas “casas tradicionais”, ou em Macuxi “Uyewî”, que significa minha casa.

Os Macuxi não sabem dizer de onde surgiu a ideia de cobrir casas com palhas de 
buriti, mas contam uma pequena história: dois Macuxi estavam caçando na serra, não se sabe dizer o local e nem a região, mas se sabe que durante essa caçada começou a chover e não havia nenhum local para se abrigarem e se protegem da chuva; conta-se que, nessa época, os Macuxi ainda moravam em locas/cavernas, mas durante essa chuva um dos Macuxi começou a observar um pequeno cogumelo, e durante essa observação ele viu que a chuva batia na parte superior do cogumelo e não atingia o tronco. A partir desse momento, ele teve a ideia de fazer uma casa que parecesse com o cogumelo, que hoje chamam de Takuusipan ou malocão; depois do malocão, veio a Parakipan, que é uma casa com formato mais comprido, mas que tinha suas pontas redondas. Segundo essa história, a partir daí, surgiu a construção das casas Macuxi.

\section{Tirar palha de buriti para cobrir casa - a explicitação de uma atividade}

Segundo Gasché e Vela (2012, p. 18), a explicitação de uma atividade permite compreender

las condiciones objetivas de vida y de la lógica de vida subjetiva implícita en el actor amazónico y sus actividades sociales, exposición, que debe crear en el lector atento y sin prejuicios la comprensión de la realidad bosquesina sobre nuevas bases conceptuales que nuestra explicitación irá definiendo. Se trata de lograr a expresar el universo objetivo que condiciona hasta cierto grado al actor bosquesino y la subjetividad de este actor en la que ejerce cierto grado de liberdad.

Nesse sentido, ao explicitar uma atividade, como tirar palha de buriti para cobrir casas, contribui-se para a compreensão das ações relacionadas ao uso de um recurso, às regras quem permeiam a atividade e a relação que se estabelece entre a sociedade e a natureza. Os detalhes permitem identificar os conhecimentos que os moradores possuem sobre o uso dos recursos e mesmo sobre a gestão do território. A retirada da palha envolve não apenas a ação de retirada, mas uma organização social, do território, uma divisão do trabalho e conhecimentos sobre a natureza. Nesse sentido, apresentamos aqui o passo a passo (explicitação) da atividade da retirada da palha de buriti para a cobertura 
da casa Macuxi e, em seguida, a ação da cobertura da casa, expressando a organização do trabalho e as relações sociais presentes.

Quadro 3 - Explicitação da atividade de retirada da palha

\begin{tabular}{|c|c|}
\hline Ação & Explicitação \\
\hline Observar a lua & $\begin{array}{l}\text { Geralmente quem faz essa observação são os homens e as } \\
\text { mulheres, por terem mais conhecimentos, quando ensinam às } \\
\text { crianças. }\end{array}$ \\
\hline $\begin{array}{l}\text { Reunir a família ou } \\
\text { comunidade para escolher a } \\
\text { data para a retirada da palha } \\
\text { de acordo com a fase da lua }\end{array}$ & $\begin{array}{l}\text { As palhas para cobertura de casa devem ser retiradas no período } \\
\text { da lua minguante, ou lua escura como eles chamam essa fase; as } \\
\text { famílias sabem quando está na época boa para tirar palha de } \\
\text { acordo com a posição da lua, quando Kapoi - lua em Macuxi - } \\
\text { aparece com seu formato pela metade às quatro da manhã. }\end{array}$ \\
\hline $\begin{array}{l}\text { Escolher o local da retirada } \\
\text { da palha }\end{array}$ & $\begin{array}{l}\text { A escolha do local é feita através de avaliações geralmente ligadas } \\
\text { à situação dos buritizais, se as folhas já estão maduras, se estão } \\
\text { baixas para poderem ser tiradas, se a área é de fácil acesso, pois a } \\
\text { água e a lama atrapalham muito. A população sempre retira } \\
\text { palhas de buritizais que estão dentro da área de limitação com } \\
\text { outras comunidades como Vista Alegre, Vista Nova e Milho, tendo } \\
\text { assim uma prática de gestão de território, através de regras } \\
\text { criadas pelas próprias lideranças da região do baixo São Marcos. } \\
\text { Isso não significa que os moradores não podem retirar palhas em } \\
\text { outras comunidades, mas, primeiramente, deve existir um acordo } \\
\text { entre elas. }\end{array}$ \\
\hline $\begin{array}{l}\text { Informar a liderança da } \\
\text { comunidade sobre a retirada } \\
\text { da palha }\end{array}$ & $\begin{array}{l}\text { Quando os pais de família vão retirar palha dentro da comunidade } \\
\text { de Campo Alegre, eles primeiramente informam ao tuxaua, em } \\
\text { seguida, ao vaqueiro; a partir daí, a notícia vai se espalhando entre } \\
\text { os outros moradores; isso é muito comum entre eles pois, de } \\
\text { certo modo, serve de prevenção para que ninguém faça } \\
\text { queimadas próximas à região onde a palha será tirada. Se na } \\
\text { comunidade, por algum período, as palhas estiverem verdes e não } \\
\text { forem suficientes para a cobertura da casa do pai de família, } \\
\text { ocorre que o tuxaua vai até outra comunidade pedir permissão } \\
\text { para tirar palha em algum local específico; se a outra comunidade } \\
\text { estiver com alguma necessidade em especial, faz-se uma troca, } \\
\text { mas isso não é uma regra. }\end{array}$ \\
\hline $\begin{array}{l}\text { Escolher quem vai usar a vara } \\
\text { com a faca ou foice para tirar } \\
\text { a palha }\end{array}$ & $\begin{array}{l}\text { Essa atividade é feita somente pelos homens, pois a vara é muito } \\
\text { pesada. }\end{array}$ \\
\hline $\begin{array}{l}\text { Escolher quem vai cortar o } \\
\text { caranã da palha }\end{array}$ & $\begin{array}{l}\text { Pode ser homem ou mulher; crianças não podem por causa do } \\
\text { uso do facão. }\end{array}$ \\
\hline
\end{tabular}




\begin{tabular}{|c|c|}
\hline $\begin{array}{l}\text { Escolher quem var arrastar } \\
\text { as palhas depois de retiradas }\end{array}$ & $\begin{array}{l}\text { Normalmente essa atividade é direcionada a crianças e } \\
\text { adolescentes. }\end{array}$ \\
\hline $\begin{array}{l}\text { Escolher quem vai contar a } \\
\text { quantidade de palhas } \\
\text { retiradas no dia }\end{array}$ & Atividade voltada para crianças e adolescentes. \\
\hline $\begin{array}{l}\text { Decidir se cada um vai } \\
\text { almoçar na sua casa ou em } \\
\text { alguma casa específica }\end{array}$ & $\begin{array}{l}\text { O almoço pode ser comunitário, dependendo se a atividade for } \\
\text { individual ou comunitária. }\end{array}$ \\
\hline $\begin{array}{l}\text { Os responsáveis pela foice e } \\
\text { faca têm que amolá-las }\end{array}$ & Tem que ser adulto e do sexo masculino. \\
\hline $\begin{array}{l}\text { A vara que vai ser usada na } \\
\text { retirada de palha deve medir, } \\
\text { aproximadamente, } 10 \text { metros }\end{array}$ & $\begin{array}{l}\text { Geralmente essas varas são feitas de bambus que são trazidos de } \\
\text { outras regiões, pois, na comunidade não há esse material. A vara } \\
\text { de tirar palha não tem uma madeira específica, os homens vão } \\
\text { para as áreas de florestas e escolhem pelo comprimento e pela } \\
\text { largura, somente quando esta é descascada e seca ao sol é que se } \\
\text { é feito o teste para saber se ela vai ser flexível e resistente o } \\
\text { suficiente para o trabalho. As famílias que não possuem varas } \\
\text { pedem emprestadas às famílias que as tem. }\end{array}$ \\
\hline $\begin{array}{l}\text { Acordar de madrugada para } \\
\text { a realização da atividade }\end{array}$ & $\begin{array}{l}\text { Esse é o melhor horário, pois a temperatura amena favorece o } \\
\text { conforto para os trabalhadores. }\end{array}$ \\
\hline $\begin{array}{l}\text { Caminhar em direção ao } \\
\text { local, dependendo da } \\
\text { distância, é o tempo para a } \\
\text { chegada }\end{array}$ & $\begin{array}{l}\text { As áreas da retirada da palha dentro da comunidade de Campo } \\
\text { Alegre são próximas. A algumas, só se pode chegar a pé, pois } \\
\text { ficam entre os igarapés. }\end{array}$ \\
\hline Chegada ao local & Os homens com as varas se dividem entre os buritizais. \\
\hline Dividir o trabalho & $\begin{array}{l}\text { Cada tirador de palha tem uma pessoa que vai arrastar a palha, } \\
\text { cortar o caranã e montar as fileiras de palhas para que outra } \\
\text { pessoa conte a quantidade. }\end{array}$ \\
\hline Suspender a atividade & $\begin{array}{l}\text { Quando a temperatura aumenta, os trabalhadores encerram a } \\
\text { retirada. }\end{array}$ \\
\hline $\begin{array}{l}\text { Transporte da palha para a } \\
\text { casa onde será feita a } \\
\text { cobertura }\end{array}$ & A pé, de moto ou camionetes. \\
\hline
\end{tabular}

A retirada da palha pode durar um dia, dependendo da quantidade desejada e do número de trabalhadores, ou durar todo o período de lua minguante. A palha não deve permanecer por muito tempo onde foi organizada em fileiras, devido à umidade do local e das prováveis chuvas que possam ocorrer, uma vez que a palha acaba apodrecendo, por não estar na devida posição em que a água possa escorrer facilmente, fazendo assim 
com que o recurso e todo trabalho sejam desperdiçados. Por esse motivo, as famílias só se reúnem para tirar as palhas quando a armação da parte superior da casa já está concluída, facilitando assim, todo o processo do término da cobertura e a prevenção de desperdício.

Dentro da comunidade indígena Campo Alegre existem vários tipos de construções de moradias, sendo elas de alvenaria, madeira e adobe cru; independe de sua estrutura inferior, a maioria da população opta pela cobertura com a palha de buriti, deixando como segunda opção a cobertura com telhas de fibrocimento. A atividade de cobrir as casas com palha de buriti vem sendo feita durante anos pelos moradores da comunidade indígena de Campo Alegre, mesmo antes deles se mudarem para região do Baixo São Marcos. Durante as entrevistas feitas com alguns moradores, foi possível notar uma relação de representação cultural do uso do buriti no dia a dia, tanto sendo utilizado no uso das confecções de artesanatos, nas ornamentações dos eventos comunitários, quanto no uso da palha para cobrir suas casas. Quando se perguntava o porquê, mesmo tendo acesso ao uso das telhas de fibrocimento, eles continuam usando a palha, as respostas eram quase sempre a mesma: uns afirmavam ser "o que o pai deles tinha ensinado para eles", ou "que quando as pessoas veem uma casa coberta de palha, já sabem que tem um Macuxi morando ali!"; outros dizem que se sentem mais confortáveis em uma casa coberta de palha de buriti do que com a telha de fibrocimento, ressaltando que a palha de buriti deixa o ambiente mais frio, diferente dos outros telhados.

A cobertura da casa com a palha considera aspectos como o momento certo para a retirada dessas palhas, como informado anteriormente.

Quando as palhas são retiradas "no tempo errado" como eles chamam, em uma semana os insetos começam a comê-la pois, segundo os Macuxi, fora da lua minguante o buriti entra em processo de transformação, como se fosse proibido fazer algo com suas palhas, que ficam com um líquido que atrai as lagartas pretas - yakî. Quando as casas são cobertas com as palhas que foram tiradas na época errada, as lagartas começam a comêlas e caem pela casa, causando desconforto para as famílias e, em pouco tempo (no intervalo de um ano), têm que ser trocadas, sendo que o tempo normal é de 10 anos, dependendo do modo de cobrir e da fase da lua. 
Durante a madrugada, começa o trabalho de partir as palhas ao meio; retira-se um pequeno talo que se encontra no meio da sua estrutura, com isso se tem a facilidade de reparti-la; normalmente se faz essa atividade durante a madrugada por causa da umidade, já que as palhas ficaram expostas ao sereno durante toda a noite, ficando mais maleáveis e sem oferecer riscos de cortes nas mãos; se a atividade de repartir a palha for feita durante a tarde, ela está seca e com as folhas bem afiadas.

As palhas são divididas em dois montes, sendo um do lado direito e o outro do lado esquerdo; essa divisão é feita para facilitar na hora de colocar as palhas nas ripas (estrutura de madeira do telhado). No dia seguinte, ainda de madrugada, começa a cobertura da casa. Durante esse processo, todos podem participar (homens, mulheres e crianças), pois ele exige muito esforço e cuidado. Essa atividade tem duas funções: uma é da pessoa que fica em cima da estrutura montada para encaixar as palhas e, a outra, é da pessoa que fica na parte interna da casa e vai entregando as palhas para a pessoa que está em cima das ripas.

O processo de cobertura começa com palhas inteiras na primeira ripa da casa, na parte inferior; isso se deve ao fato de que essas primeiras palhas sustentarão as outras, e se forem colocadas partidas, elas se desgastarão facilmente; e, em seguida, a segunda ripa é preenchida com palhas partidas, podendo ser direita ou esquerda.

Esse processo é feito revezando uma ripa com palhas do lado direito e a outra do lado esquerdo, até chegar à parte mais alta que é chamada de "capote", onde se colocam palhas menores em direções contrárias, formando assim uma espécie de escorredor, para que a água da chuva não se acumule.

O trabalho de cobrir uma casa com palhas pode durar um dia ou mais, dependendo apenas da quantidade de pessoas que participarão dessa atividade.

\section{Retirada de palhas e a gestão do recurso}

Segundo as pessoas entrevistadas (os Macuxis), os buritizais eram abundantes quando os primeiros moradores indígenas chegaram à região. Eles não conseguiam 
imaginar que um dia teriam dificuldades em encontrar locais para a retirada da palha. Conta-se que, no início, eles não precisavam de varas compridas para poder tirar palhas grandes e maduras; atualmente, as palhas são pequenas e, por isso, precisam ser retiradas em maior quantidade, retardando assim a sua renovação.

Outra observação feita pelos entrevistados (indígenas) é sobre a falta de preocupação de alguns moradores que produzem artesanato com a fibra do olho do buriti. A retirada constante do olho de um mesmo buriti impede o seu crescimento tornando-a, assim, uma árvore com pouca utilidade, tanto para as pessoas, quanto para os outros seres que também precisam dessa fonte, uma vez que fornece abrigo para diversas aves, alimentação para os animais da região e para o próprio consumo da população.

Durante a pesquisa, foi possível identificar vários problemas ambientais relacionados ao buriti e como estes são constantes e muitas vezes passam despercebidos pela própria população que habita a comunidade de Campo Alegre. Esses problemas surgem a partir do modo de organização da comunidade estudada, com a inserção da criação de gado e cavalos criados soltos. Estes passam a maior parte do tempo às margens dos igarapés Grande e Nevi, e o pisoteamento causado pelo seu caminhar impede que os cursos de água possam fluir normalmente, principalmente no período em que se inicia o verão. É de conhecimento dos vaqueiros a necessidade de fazer queimadas para a renovação do capim de que o gado se alimenta e, em muitas dessas queimadas programadas, acaba ocorrendo um descontrole que afeta os buritizais, matando as árvores que ainda estão brotando e enfraquecendo o tronco dos buritizeiros mais velhos.

Como já mencionado anteriormente, o desperdício de palhas, quando não são retiradas "no tempo certo", que é a lua minguante, é um indicativo de que é preciso resgatar os conhecimentos tradicionais para o manejo dos buritizais. Segundo os entrevistados, o número de palhas perdidas chega a 2.500 em algumas coberturas de casas. Esse número corresponde ao modelo mais comum de casa construída na comunidade indígena Campo Alegre. É de conhecimento da própria população local indígenas que, para que haja palhas maduras, é necessário que se faça um intervalo de quatro anos para que o buritizeiro possa ser utilizado novamente. Esse cuidado com o 
tempo necessário para a recomposição do buritzal já configura um tipo de manejo, porém com o crescimento da população, a construção de novas casas, além da renovação de coberturas, temos a demanda por mais palha e, nesse contexto, somente essa técnica tradicional não tem contemplado a recuperação dos buritizais, o que tem se configurado como um problema a ser resolvido e um desafio para a comunidade Campo Alegre.

\section{Considerações finais}

Apesar do fácil acesso a materiais industrializados na cidade de Boa Vista, os moradores da comunidade indígena Campo Alegre não abrem mão do saber tradicional relacionado ao uso da palha de buriti na cobertura das casas, entre outros recursos existentes na região. A relação do povo Macuxi não é apenas ligada a questões materiais e econômicas, mas sim ao lado histórico e cultural que é repassado diariamente pelas ações e diálogos entre as famílias, em que os mais velhos, juntamente com os mais novos, ensinam e aprendem. Através das observações, o homem, e em especial o indígena, consegue compreender o funcionamento dos diversos aspectos da natureza, sendo esta considerada o elemento fundamental para a vida.

Essa relação cultural do povo Macuxi com a natureza influencia bastante na preocupação com a preservação dos principais recursos encontrados na região, em especial o buriti, que envolve todo um sistema de abastecimento para a população, pois a falta de manejo com o uso dos saberes tradicionais, principalmente os conhecimentos astronômicos, resulta num impacto que já é bastante visível. Com o aumento da população indígena, surge a necessidade de se construírem mais casas e, com isso, mais buritizais serão utilizados nestas construções. A retirada de palha com o uso da técnica e dos conhecimentos tradicionais tem a capacidade de preservar e manter um buritizal, quando se observam as condições gerais das plantas e se aguarda o intervalo de quatro anos para a reutilização da área. Os problemas ambientais não são provocados pelos indígenas, mas pela falta de políticas ambientais que assegurem a reprodução do buriti.

Segundo os entrevistados (indígenas), as instituições, tanto governamentais como não governamentais, não investem em políticas de preservação ambiental ou de 
recuperação de áreas degradadas. Os projeto que chegam são direcionados à criação de animais para corte, lavouras e até mesmo para o plantio de vegetação que não é nativa, como a monocultura de eucalipto.

Acredito que é importante manter o conhecimento tradicional e repassá-lo para os mais jovens e para toda a comunidade, pois em parte, essa população é composta por não indígenas e indígenas que não fazem o uso desses saberes, tanto na preservação da vegetação local, na organização de locais específicos para a criação do gado ou na preocupação do uso artesanal feito com o olho de buriti.

A principal aprendizagem durante a realização desta pesquisa foi a possibilidade de poder construir o calendário socionatural a partir do ponto de vista de cada entrevistado, em que se observa a grande semelhança da prática de saberes de cada família, de como a comunidade se organiza, dos problemas e dificuldades enfrentados e suas perspectivas voltadas ao uso da terra. Como acadêmica do curso de Gestão Territorial Indígena, durante a pesquisa dos temas contextuais e as atividades realizadas no Observatório de Educação Escolar Indígena/OBEDUC, tive a oportunidade de conhecer comunidades de outros povos indígenas e a relação com o território ocupado por eles e, através do calendário socionatural, pude compreender melhor as relações entre os saberes tradicionais que cada comunidade ou povo tem com a natureza.

Através do histórico da criação da comunidade indígena Campo Alegre, foi possível ressaltar o principal fator que levou à escolha do local pelos primeiros moradores, que foi a abundância dos buritizais, seguida dos recursos hídricos que favoreciam no sustento das famílias e de como é feita a organização social atualmente; tudo está relacionado aos saberes culturais ainda presentes nas atividades, sendo elas comunitárias ou individuais.

Enfim, a elaboração desta pesquisa me permitiu estar em maior contato com a minha comunidade de origem e com os saberes tradicionais do meu povo Macuxi. Apesar de já possuir alguns conhecimentos que me foram repassados por familiares, conversar com outros moradores me fez ter uma visão diferente da vida das pessoas na comunidade e do vínculo criado pelos que chegaram de outras localidades e se instalaram 
ali. A importância da pesquisa vem justamente da necessidade que ainda se tem de trabalhos voltados para as questões territoriais e socioambientais relacionadas aos saberes tradicionais de cada povo, em especial na região do baixo São Marcos - TISM. O uso dos saberes tradicionais em trabalhos acadêmicos realizados por estudantes indígenas de graduação reforça a importância dos saberes da população indígena como mantenedores dos recursos naturais, muitos deles ameaçados e que são esgotáveis, antiga fala das lideranças indígenas que há muito tempo já se mostravam preocupadas com a situação em que a sua terra poderia se encontrar.

\section{Referências}

BARBOSA, R. I.; LIMA, A. D.; MOURÃO JUNIOR, M. Biometria de frutos de buriti (Mauritia flexuosa L. F. - aracaceae): produção de polpa e óleo em uma área de savana de Roraima. Amazônia: Cl e Desenvolvimento, Belém, v. 5, n. 10, p. 71-85, jan./jun., 2010.

BARBOSA, R. I. Ocupação humana em Roraima: do histórico colonial ao início do assentamento dirigido. Boletim do Museu Paraense Emílio Goeldi, Belém, n. 9, p. 123-144, 1993.

ETHONICO, M. B. M. Gestão territorial em áreas indígenas: a contribuição da universidade. In: VAL, A. L.; MELO FILHO, A. A.; WANKLER, F. L (Orgs.). Universidade, ciência e pesquisa na Amazônia: os desafios da produção intelectual. Boa Vista: Editora da UFRR, 2012. p. 103-130.

CEDRO, W. L.; MOURA, M. O. As relações entre a Organização do Ensino e a Atividade de Aprendizagem. In: LIBERALI, F.; MATEUS, E.; DAMIANOVIC, M. C. (Orgs.). A teoria da atividade sócio-histórico-cultural e a escola: recriando realidades sociais. Campinas: Pontes Editores, 2012. p. 43-59.

GASCHÉ, J. S.; VELA, N. M. Sociedad bosquesina: Ensayo de antropología rural amazónica, acompañado de una crítica y propuesta alternativa de proyectos de desarrollo. Iquitos, Perú: Instituto de Investigaciones de la Amazonía Peruana (IIAP); Lima, Perú: Consorcio de Investigaciones Económicas y Sociales (CIES); Japón: Center for Integrated Area Studies, Kyoto University (CIAS); 2012.

MANDUCA, L. S.; SILVA, N. M.; ALMEIDA, F. T. Atlas escolar: terra indígena São Marcos. Boa Vista: Editora da UFRR,2009. 
REPETTO, M.; CARVALHO, F. Experiencias de investigación educativa intercultural en la formación de maestros indígenas en Roraima, Brasil. Desacatos, México, n. 48, p. 50-65, maio/ago., 2015.

RESENDE, I. L. M. et al. Estrutura Etária de Populações de Mauritia flexuosa L. F. (Arecaceae) de Veredas da Região Central de Goiás, Brasil. Revista Árvore, Viçosa-MG, v.36, n.1, 2012, p.103-112.

VIEIRA, J. G.; GOMES FILHO, G. F. Forte São Joaquim: do marco da ocupação portuguesa do Vale do Rio Branco às batalhas da memória - século XVIII ao XX. Textos e Debates, Boa Vista. n. 20. p. 101-119. Jan./jun., 2013. 